Article

\title{
Effects of protection on amount and structure of forest cover at two scales in Bozin and Marakhil protected area, Iran
}

\author{
Azad Henareh Khalyani ${ }^{1, *}$, Audrey L. Mayer ${ }^{1}$ and Michael J. Falkowski ${ }^{1}$ \\ ${ }^{1}$ School of Forest Resources and Environmental Science, Michigan Technological University, \\ Houghton, MI 49931,USA
}

E-Mails: ahenareh@mtu.edu ; almayer@mtu.edu ; mjfalkow@mtu.edu (1400 Townsend Drive, Houghton MI, 49931, USA.)

* Author to whom correspondence should be addressed; Tel.: +1-906-231-1186; Fax: +1-906-4872519 (1400 Townsend Drive, Houghton MI, 49931, USA.)

Received: / Accepted: / Published:

\begin{abstract}
Official protection can play a major role in the conservation of biodiversity and sustainable management of endangered species habitat. Bozin and Marakhil Forest in Kermanshah province of Iran covers 23,724 ha of semi-arid Zagros forests. It was designated as a protected habitat area for Eurasian roe deer (Capreolus capreolus) in 1999, a species that thrives on forest edge habitat. Using remote sensing data from 2001 and 2009, we evaluated the effects of this protected designation on forest area and structure at two spatial scales. We processed and classified Landsat images for the two dates covering the protected area and the adjacent unprotected areas for the broad scale analysis. We classified IKONOS and GeoEye images of the two dates covering a part of protected and unprotected areas for fine scale analysis. Protection had a scale dependent influence on habitat availability and structure. A small difference due to protection at the fine scale was increased fractal dimension of forest patches as a measure of habitat complexity, likely due to reduced human impact. The official protection maintained habitat availability, contiguity, and complexity at the broad scale, probably at the expense of increasing human pressure on the surrounding unprotected areas. Given this scale dependency of protection effects on habitat amount and structure, the actual effects of protection would depend on the practical home range size and scale at which species use the habitats.
\end{abstract}


Keywords: Bozin and Marakhil Protected Area; habitat protection; roe deer; landscape structure; scale; local communities. 


\section{Introduction}

The efficiency and sustainability of protected areas for biodiversity conservation has been debated from many perspectives [1-3]. Gaston et al. (2008) did a synthetic review on this issue and identified several knowledge gaps, including the effect of protected areas on the restoration of biodiversity features, the relative ecological performance of protected areas, and interaction between populations within and outside protected areas. Forest cover is one of the most important indicators of sustainable landscape management [4] since it shows the total amount of natural and socio-economical resources as well as habitat for forest-dependent species. However, detection of changes in forest cover is not enough per se, since management practices or protection may significantly change the habitat structure that is critical for endangered species maintenance and conservation.

Landscape structure metrics have been demonstrated to be useful sustainability indicators for forested ecosystems, and forest spatial structure in particular has been identified as particularly valuable [5-9]. Of main interest here is the effect of protection on disturbance regime and landscape structure [10-11]. However the significance of these effects and structural patterns is strongly dependent on the scale of observation [7, 12-17]. Therefore it is necessary to investigate the effect of protection on habitat area and structure at different scales, and its consequences for sustainable conservation of focal species in a given socioeconomic context.

In this study we use remotely sensed data at two scales, including both grain and extent, to evaluate the effects of eight years of protection on forest cover and landscape structure in a semi-arid Mediterranean landscape. We evaluate the efficiency of protection in relation to habitat requirements of roe deer (Capreolus capreolus). We hypothesize that the protected and unprotected areas form two different landscape types that might be discriminated using landscape metrics, but that these differences may not be the same at different scales. We suggest that these changes in landscape structure inside and outside of the protected area has considerable implications for sustainable species conservation and local community stewardship through removing land from human access.

\section{Methods}

\subsection{Study area}

The Zagros forest region extends from the northwest of Iran to the southeast (Figure 1). It is semiarid with a continental climate, with average annual precipitation of $\approx 50 \mathrm{~mm}$ which varies between $350 \mathrm{~mm}$ and $\approx 1000 \mathrm{~mm}$ [18]. The Bozin and Marakhil Forest is a protected area in the Kermanshah province of Iran, and covers 23,724 ha of semi-arid Zagros oak forests (Figure 1). The western border of the protected area is delineated by the Sirvan River which is also the Iran-Iraq border. It was designated as a protected area in 1999 to preserve habitat for Eurasian roe deer (Capreolus capreolus) which has been locally extinct in some other countries of the region such as Lebanon, Israel, Syria and Iraq since the beginning of $20^{\text {th }}$ century, and in Jordan since the beginning of the $19^{\text {th }}$ century [19]. Forests in the study area are used similarly to forests throughout the Zagros region, primarily for traditional activities such as livestock grazing and browsing, defoliation and disbranching of trees, cutting for fuel and construction, collecting fruits and oak acorns, conversion of forests to dry cultivation land, and utilization of forest products [18]. More recently, fire frequency has been 
increased in both protected and surrounding unprotected areas due to human activity. In this study, we compare two typical semi-arid patchy forest landscapes of same soil and landforms, one after eight year of protection and the other which remained unprotected. Protection in Iran imposes formal legal restrictions on hunting, harvesting and other traditional usages, but enforcement can be sporadic at times.

Figure 1. Location of the Bozin and Marakhil protected area in the Zagros forest region, western Iran.

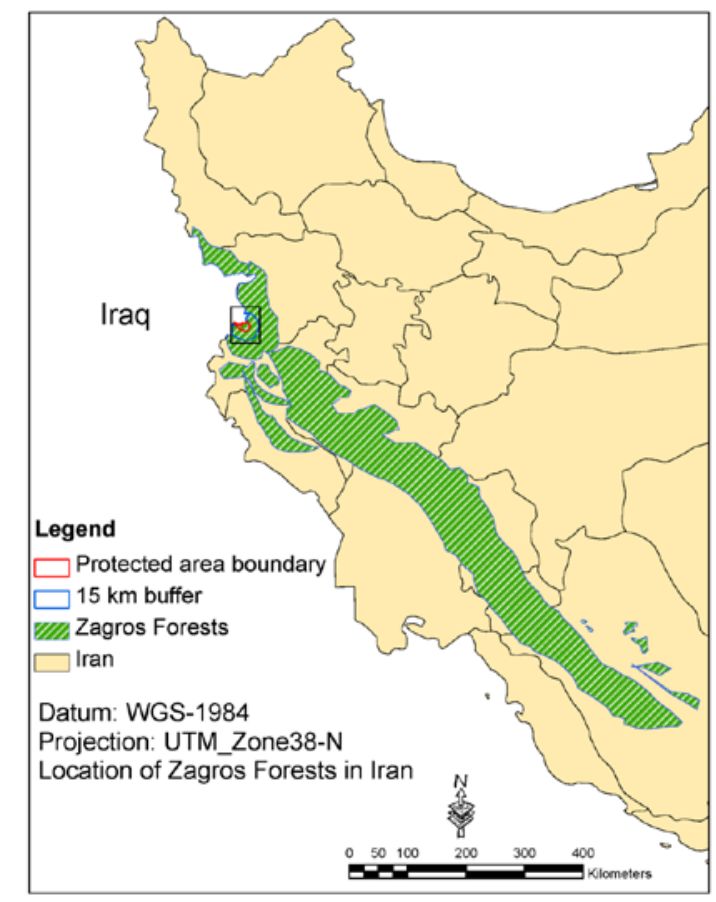

\subsection{Delineation of the study area and scale of the study}

The extent of the protected area was digitized in a Geographic Information System (GIS; Figure 2). The data were obtained at two different scales and all analyses were conducted independently at the two scales. The Landsat-5 Thematic Mapper images of 2001 and 2009 covering the study area (WRS2, Path 168, and Row 36) were obtained from the U. S. Geological Survey portal [20] and used for a broad scale analysis. This broad scale analysis has a 30m grain size and $\sim 6750000$ ha extent that included the entire protected area and a $15 \mathrm{~km}$ unprotected buffer surrounding the protected area. This buffer was used to avoid problems associated with autocorrelation and directionality when calculating landscape metrics. The unprotected areas that were located in Iraq were clipped out of the analysis to avoid the bias associated by different socioeconomic conditions and national management approaches in the two countries. An IKONOS image covering some protected and unprotected areas in 2001, and two GeoEye images covering a part of the protected area and unprotected buffer in 2009 were obtained and used for the fine scale analysis (Figure 2). This fine scale analysis has a 1m grain size and 16500 ha extent. 
Figure 2. Protected area, unprotected $15 \mathrm{~km}$ buffer and the coverage of fine scale high resolution imagery.

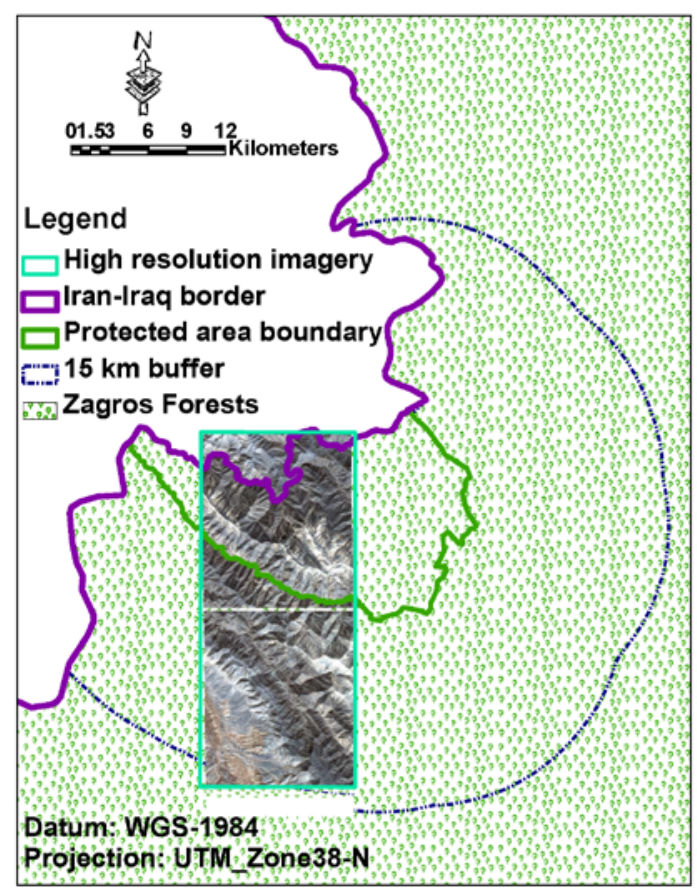

\subsection{Image processing and classification}

We georectified the Landsat images based on the orthorectified images (of the same path and row) acquired from the global Landsat GeoCover archive [21] using a third order polynomial model and nearest neighbor resampling in the image-to-image registration to obtain the required spatial accuracy (RMSE $<15 \mathrm{~m})$. We applied radiometric correction to each image based on current radiometric calibration coefficients for Landsat MSS, TM, and ETM [22].

We calculated spectral variables that have previously been found to be effective for land cover classification across semi-arid regions, including Normalized Difference Vegetation Index [23], and Soil Adjusted Vegetation Index [24]; and data transformations such as tasseled cap transformation [25]; and principal component analysis [26]. We included six topographic variables including elevation, slope, transformed aspect [27], Bolstad's land form [28], and flow accumulation, assuming that the extreme topographic variation across the Zagros region strongly influences temperature and moisture gradients and hence land cover types. We obtained the topographic metrics from the $90 \mathrm{~m}$ Digital Elevation Model (DEM) acquired via NASA's Shuttle Radar Topographic Mission [29]. In total, we calculated 33 predictor variables for the Landsat TM images in each year.

We used the Random Forest (RF) algorithm [30] with a recent application in the classification of remotely sensed data [31-35] for the classification of Landsat images based on the spectral and topographic variables discussed above. We used high resolution images available on Google Earth as a reference for Landsat images. We classified the IKONOS and GeoEye images by density slicing of the Normalized Difference Vegetation Index (NDVI). Given the large amount of detail in these high resolution images, NDVI values were sufficient to successfully differentiate trees from other vegetation. We used ERDAS Imagine 2010 software [36] and ArcMap v.9.3 [37] for image processing 
and GIS analyses. We used the Random Forest package [38] in the R statistical program [39] for the classification of Landsat images.

\subsection{Variable selection and statistical analysis}

All available 45 landscape metrics at the patch level were calculated in Fragstats [40]. Since the spatial pattern metrics are usually highly correlated [6, 41, 42], we used a multivariate factor analysis based on Principal Component Analysis (PCA) and Varimax rotation to reduce data dimensionality. The criterion for selecting the metrics was the loadings on the factors [41]. The normality tests of the selected metrics showed that none of them were normally distributed at either scale of the analysis, and could not be transformed to normal distributions using common transformation methods [43]. Additionally, the comparison of the two landscapes in this study is an example of pseudoreplication [44], and using statistical inference in these types of comparisons is likely to be biased. Since we compared landscape metrics at the patch level, each of the two protected and unprotected treatments have sufficient sample replication. We used the non-parametric Wilcoxon rank sum test [45] to compare the landscape metrics between protected and unprotected areas and through time. We applied factor analysis using SPSS statistics v.17 [46].

\section{Results and Discussion}

\subsection{Variable selection}

A preliminary PCA of all 45 landscape metrics at the patch level showed significant relationships $(\mathrm{P}<0.001)$. We identified four factors based on Kaiser's criterion [47]. The four factors explained 97\% of the variation in the dataset. Metrics of patch extension including patch area (AREA) and radius of gyration (GYRATE) had the highest loadings on the first factor. Euclidean Nearest Neighbor distance (ENN) was the metric with prominent loading on the second factor. Contiguity index (CONTIG) and fractal dimension (FRAC) were the metrics with the highest loadings on the third and fourth factors respectively. Therefore, four independent patch level metrics AREA, ENN, CONTIG, and FRAC were selected to detect changes in patch extent, patch isolation, contiguity, and landscape complexity respectively, at both scales.

\subsection{Landscape structure analysis at broad scale}

The analysis of landscape structure metrics across space at the broad scale showed that the protected and unprotected areas did not show significant differences in the values of the forest patch level structural metrics at the beginning of the study period in 2001, except for ENN which was shorter for the protected areas (Table 1). The structural metrics with the exception of FRAC became significantly different between protected and unprotected areas in 2009. Forest patches in the protected areas were larger with higher extension, were less isolated, and more contiguous than the ones in the unprotected area in 2009 (Table 1). Both areas showed a comparable total habitat loss at the landscape scale (Figures 3a and 4a). 
Table 1. Comparison between protected and unprotected areas at the broad scale in 2001 and 2009. Statistically significant $\mathrm{p}$ values are denoted in bold. $\mathrm{P}, \mathrm{U}$, and $\chi^{2}$ denote protected, unprotected, and Wilcoxon's chi square respectively.

\begin{tabular}{|c|c|c|c|c|}
\hline \multicolumn{5}{|c|}{2001} \\
\hline \multirow{2}{*}{ Metric } & \multirow{2}{*}{$\chi^{2}$} & \multirow{2}{*}{$\mathrm{P}$ value } & \multicolumn{2}{|c|}{ Medians } \\
\hline & & & $\mathrm{P}$ & $\mathrm{U}$ \\
\hline AREA (ha) & 2.44 & 0.1183 & 0.1584 & 0.1584 \\
\hline ENN (m) & 20.22 & 0.0000 & 56.2823 & 62.9256 \\
\hline CONTIG & 2.24 & 0.1344 & 0.0833 & 0.1667 \\
\hline FRAC & 2.68 & 0.1017 & 1.0160 & 1.0160 \\
\hline \multicolumn{5}{|c|}{2009} \\
\hline \multirow{2}{*}{ Metric } & \multirow{2}{*}{$\chi^{2}$} & \multirow{2}{*}{$\mathrm{P}$ value } & \multicolumn{2}{|c|}{ Medians } \\
\hline & & & $\mathrm{P}$ & $\mathrm{U}$ \\
\hline AREA (ha) & 5.83 & 0.0157 & 0.1575 & 0.0788 \\
\hline ENN (m) & 22.94 & 0.0000 & 56.1285 & 62.7536 \\
\hline CONTIG & 6.23 & 0.0126 & 0.0833 & 0.0000 \\
\hline FRAC & 2.60 & 0.1072 & 1.0000 & 1.0000 \\
\hline
\end{tabular}

Table 2. Comparison between the condition of the protected and unprotected areas from 2001 to 2009 at the broad scale. Statistically significant $\mathrm{p}$ values are denoted in bold. $\chi^{2}$ denotes Wilcoxon's chi square.

\begin{tabular}{lllll}
\hline \multicolumn{5}{c}{ Protected } \\
\hline \multirow{2}{*}{ Metric } & \multirow{2}{*}{$\chi^{2}$} & P value & \multicolumn{2}{c}{ Medians } \\
\cline { 4 - 5 } & & & 2001 & \multicolumn{1}{c}{2009} \\
\hline AREA (ha) & 82.24 & $\mathbf{0 . 0 0 0 0}$ & 0.1584 & 0.1575 \\
ENN (m) & 114.04 & $\mathbf{0 . 0 0 0 0}$ & 56.2823 & 56.1285 \\
CONTIG & 0.15 & 0.7033 & 0.0833 & 0.0833 \\
FRAC & 0.07 & 0.7959 & 1.0160 & 1.0000 \\
\hline \multicolumn{3}{r}{ Unprotected } \\
\hline \multirow{2}{*}{ Metric } & $\chi^{2}$ & P value & \multicolumn{2}{c}{ Medians } \\
\cline { 4 - 6 } & & & \multicolumn{1}{c}{2001} & \multicolumn{1}{c}{2009} \\
\hline AREA (ha) & 1763.81 & $\mathbf{0 . 0 0 0 0}$ & 0.1584 & 0.0788 \\
ENN (m) & 864.48 & $\mathbf{0 . 0 0 0 0}$ & 62.9256 & 62.7536 \\
CONTIG & 136.55 & $\mathbf{0 . 0 0 0 0}$ & 0.1667 & 0.0000 \\
FRAC & 87.43 & $\mathbf{0 . 0 0 0 0}$ & 1.0160 & 1.0000 \\
\hline
\end{tabular}

The analysis of the metrics across time showed that the protection did not have any significant effect on the landscape structure of the protected areas. Patch extension decreased from 2001 to 2009 and consequently the ENN was shorter. Contiguity and complexity of the landscape did not change in 
the protected area at this scale (Table 2). The unprotected area however showed a substantial decrease in patch extension, patch isolation, contiguity and fractal dimension. Fractal dimension has been reported to be a good measure of human impact [48-50]; the significant decrease in fractal dimension showed the trend of the landscape towards more simplified forest patterns due to human utilizations in unprotected areas at the broad scale (Table 2). This shows that protection was not able to halt habitat loss and fragmentation, but it kept the contiguity and complexity of the landscape in a stable state. The significant difference between protected and unprotected areas in 2009 (Table 1) is due to the high amount of fragmentation in the unprotected area and not to any improvement in the protected area. Protection probably causes more resource extraction pressure on the surrounding unprotected areas.

Figure 3. Total forest cover change in the (a) broad scale, (b) fine scale

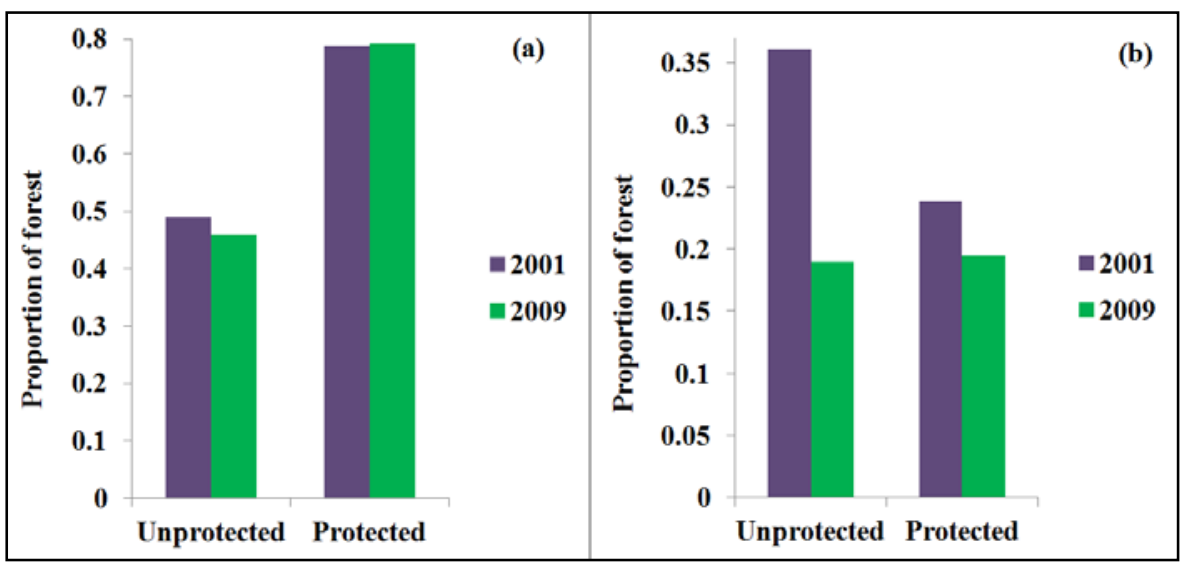

\subsection{Landscape structure analysis at fine scale}

The comparison of the selected metrics between the protected and unprotected areas at the fine scale in 2001 showed that the sites are structurally different at this scale in 2001 (Table 3). It shows that the protected area contained less fragmented forest stands. With the exception of landscape complexity (which was lower for the protected area at this scale), the protected area seems to be structurally better than the unprotected area at this scale in 2001 (Table 3), even though no difference in structure was found at the broad scale in 2001 (Table 1). Higher patch extent and contiguity and lower fractal dimension is characteristic of the protected area compared to the unprotected area at the fine scale in 2001 (Table 3). The same comparisons in 2009 showed that the protected area again had higher patch area and contiguity (Table 3), as well as an improvement of landscape complexity at the end of the study period. This was shown by non-significant difference in fractal dimension between two sites in 2009 compared to its higher value for unprotected area in 2001 (Table 3). Most of the structural differences between the protected and unprotected areas already existed in 2001 and might not be due to protection, except for fractal dimension which increased in the protected area (Table 4) and decreased in the unprotected areas (Table 4). The protected area had lower fractal dimension in 2001, but it had the same value of fractal dimension as the unprotected area in 2009. The analysis of structural change from 2001 to 2009 showed that in both protected and unprotected areas, patch extent 
and contiguity decreased, and ENN increased, from 2001 to 2009 (Table 4). Both protected and unprotected areas became significantly more fragmented through time with less habitat area. Although both habitat area (AREA) losses in protected and unprotected areas were statistically significant at this scale, the total habitat loss at the landscape scale showed that this change was more visible for unprotected area (Figures 3b and 4b). Protection resulted in more structurally complex landscapes displayed by changes in fractal dimension in both protected and unprotected areas (Tables 3 and 4) and that was a small effect at the fine scale. Given the ongoing socioeconomic conditions in the area and the dependence of the local communities on forest products, we would assume that physical protection is not being actively enforced and remains nominally effective. Although the effect of protection on habitat availability is more visible at the broad scale (Tables 1 and 2), it is at the expense of putting more pressure from local communities on the surrounding unprotected areas.

Figure 4. View of changes in amount and structure of habitats at two spatial scales: (a) broad scale by Landsat imagery, (b) fine scale by IKONOS and GeoEye imagery.

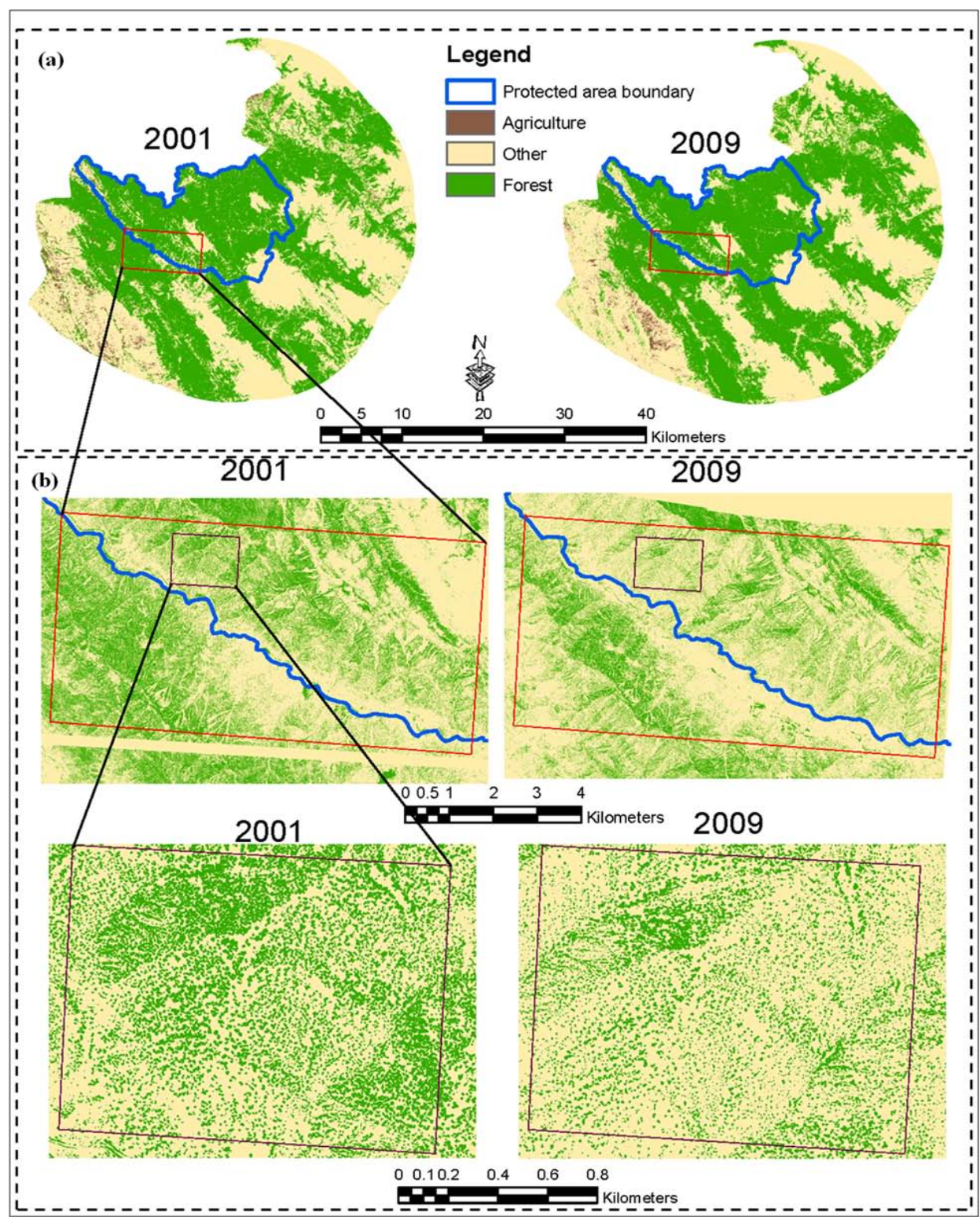


Table 3. Comparison between protected and unprotected areas at the fine scale in 2001 and 2009. Statistically significant p values are denoted in bold. P, U, and $\chi^{2}$ denote protected, unprotected, and Wilcoxon's chi square respectively.

\begin{tabular}{|c|c|c|c|c|}
\hline \multicolumn{5}{|c|}{2001} \\
\hline \multirow{2}{*}{ Metric } & \multirow{2}{*}{$\chi^{2}$} & \multirow{2}{*}{$\mathrm{P}$ value } & \multicolumn{2}{|c|}{ Medians } \\
\hline & & & $\mathrm{P}$ & $\mathrm{U}$ \\
\hline AREA (ha) & 380.46 & 0.0000 & 0.0019 & 0.0018 \\
\hline ENN (m) & 140.98 & 0.0000 & 3.0000 & 3.0000 \\
\hline CONTIG & 672.46 & 0.0000 & 0.6778 & 0.6667 \\
\hline FRAC & 369.56 & 0.0000 & 1.1359 & 1.1429 \\
\hline \multicolumn{5}{|c|}{2009} \\
\hline \multirow{2}{*}{ Metric } & \multirow{2}{*}{$\chi^{2}$} & \multirow{2}{*}{$\mathrm{P}$ value } & \multicolumn{2}{|c|}{ Medians } \\
\hline & & & $\mathrm{P}$ & $\mathrm{U}$ \\
\hline AREA (ha) & 104.58 & 0.0000 & 0.0013 & 0.0011 \\
\hline ENN (m) & 927.75 & 0.0000 & 3.6056 & 3.6056 \\
\hline CONTIG & 178.23 & 0.0000 & 0.5873 & 0.5556 \\
\hline FRAC & 2.80 & 0.0941 & 1.1386 & 1.1386 \\
\hline
\end{tabular}

Table 4. Comparison between the condition of the protected and unprotected areas from 2001 to 2009 at the fine scale. Statistically significant $\mathrm{p}$ values are denoted in bold. $\chi^{2}$ denotes Wilcoxon's chi square.

\begin{tabular}{lllll}
\hline \multicolumn{5}{c}{ Protected } \\
\hline \multirow{2}{*}{ Metric } & \multirow{2}{*}{$\chi^{2}$} & \multirow{2}{*}{ P value } & \multicolumn{2}{c}{ Medians } \\
\cline { 4 - 5 } & & & 2001 & 2009 \\
\hline AREA (ha) & 3436.29 & $\mathbf{0 . 0 0 0 0}$ & 0.0019 & 0.0013 \\
ENN (m) & 11661.02 & $\mathbf{0 . 0 0 0 0}$ & 3.0000 & 3.6056 \\
CONTIG & 4409.62 & $\mathbf{0 . 0 0 0 0}$ & 0.6778 & 0.5873 \\
FRAC & 567.87 & $\mathbf{0 . 0 0 0 0}$ & 1.1359 & 1.1386 \\
\hline \multicolumn{5}{c}{ Unprotected } \\
\hline \multirow{2}{*}{ Metric } & $\chi^{2}$ & P value & \multicolumn{2}{c}{ Medians } \\
\cline { 4 - 5 } AREA (ha) & 6904.29 & $\mathbf{0 . 0 0 0 0}$ & 0.0018 & 0.0011 \\
ENN (m) & 6155.92 & $\mathbf{0 . 0 0 0 0}$ & 3.0000 & 3.6056 \\
CONTIG & 9479.24 & $\mathbf{0 . 0 0 0 0}$ & 0.6667 & 0.5556 \\
FRAC & 55.46 & $\mathbf{0 . 0 0 0 0}$ & 1.1429 & 1.1386 \\
\hline
\end{tabular}

\subsection{Structural metric change across scales}

Habitat availability (in terms of forest patch area) decreased significantly in both protected and unprotected areas at both scales. ENN changed differently in response to the change to AREA at the two scales. At the broad scale ENN decreased as AREA increased. Although at the broad scale 
fragmentation caused divisions in larger patches and resulted in shorter distances between remaining smaller patches, at the fine scale where the patches are single trees, the loss of a tree results in larger distances between remaining trees (ENN). Landscape contiguity significantly decreased in both areas at the fine scale (Table 3), but the effect was not significant when aggregated at the broad scale in the protected area, whereas it was significant in the unprotected area (Table 2). The landscapes became more structurally complex in the protected area and simpler in the unprotected area at fine scale. However, the aggregated effect at the broad scale was only significant in the unprotected area.

\section{Conclusions}

The efficiency of protection depends on its effects on habitat availability and structure, and the socioeconomic consequences at both scales. Our results show that protection did not significantly improve the resource availability (forests) at either scale studied, because patch area significantly decreased in both protected and unprotected forests at both scales. The difference already existed at the fine scale (Table 3). However, protection did maintain more forest when looking from a broad scale. Changes in habitat contiguity at the fine scale could not be attributed to protection effects because it changed similarly in protected and unprotected areas at this scale, but protection induced more complexity at this scale (Table 4). Protection also maintained habitat contiguity and complexity at the broad scale which were destroyed in unprotected areas. In total, given the patterns and intensity of local resource use, the effects of protection did act to buffer the human impacts and thus improved landscape complexity at the fine scale, and when the data are aggregated these effects are even more pronounced. The less fragmented landscape had less ecosystem variability [51], but in total it supported higher habitat availability or forest cover. Roe deer population in the area has been found to be heavily dependent upon areas with higher canopy cover [52], different than in Europe where higher populations of roe deer reside in open areas than in forests [53, 54]. However, the protection of unfragmented forest comes at the expense of higher utilization pressure on the surrounding unprotected areas, which may decrease $\beta$ diversity [55]. Extending forest protection outside the park will require the cooperation of local communities and would result in more efficient and sustainable protection at both scales.

Roe deer is a habitat generalist species with behavioral plasticity [56-59], although the scale at which roe deer perceive its environment is not clear. The disparate effects of protection at different scales suggests that effective habitat protection will at least partially depend on details such as roe deer home range size and the scale at which the species responds to habitat change [60]. Relative to larger deer, roe deer should have small home ranges based on its energetic constraints and mobility. However, its home range size may also be influenced by other factors such as reproductive success and resource availability [61]. These factors are, in turn, dependent upon the ecological conditions in the area. This study contributes an important new question for the discussion regarding strict protected areas as a means of biodiversity, and its socioeconomic effects on local communities [62, 63]. If these areas are meant to protect particular species, the size and boundaries of the area must be influenced by the species' life history, and the impact of protection on habitat outside of the area should be 
considered. Increasing the intensity of resource use outside park boundaries may create barriers for dispersal, effectively creating habitat islands out of a park.

\section{Acknowledgments}

This project was partially funded by the Michigan Space Grant Consortium.

\section{Conflict of Interest}

The authors declare no conflict of interest

\section{References and Notes}

1. Mayer, A.L. Putting the right parks in the right places (book review). Ecology 2003, 84, 273-274.

2. Gaston, K.J.; Jackson, S.F.; Cantú-Salazar, L.; Cruz-Piñón, G. The ecological performance of protected areas. Annual Review of Ecology, Evolution, and Systematics 2008, 39, 93-113.

3. Rands, M.R.W.; Adams,W.M.; Bennun, L.; Butchart, S.H.M.; Butchart, A.; Coomes, D.; Entwistle,A.; Hodge, I.; Kapos,V.; Scharlemann J.P.W. Biodiversity conservation: challenges beyond. Science 2010, 329, 1298-1303.

4. Maestre, F.; Escudero, A. Is the patch size distribution of vegetation a suitable indicator of desertification processes? Ecology 2009, 90, 1729-1735.

5. Loyn, R.H.; McAlpine, C.; Raison, R.J.; Brown, A.G.; Flinn, D.W. Spatial patterns and fragmentation: indicators for conserving biodiversity in forest landscapes; CABI Publishing: New York, USA, 2001; pp. 391-422.

6. Gustafson, E.J. Quantifying landscape spatial pattern, what is the state of the art? Ecosystems 1998, 1, 143-156.

7. Lausch, A.; Herzog, F. Applicability of landscape metrics for the monitoring of landscape change: issues of scale, resolution and interpretability. Ecological Indicators 2002, 2, 3-15.

8. Kruess, A. Effects of landscape structure and habitat type on a plant herbivore parasitoid community. Ecography 2003, 26, 283-290.

9. Mayer A.L.; Cameron, G.N. Landscape characteristics, spatial extent, and breeding bird diversity in Ohio. Diversity and Distributions 2003, 9, 297-311.

10. Mladenoff, D.J.; White, M.A.; Pastor, J.; Crow, T.R.. Comparing spatial pattern in unaltered oldgrowth and disturbed forest landscapes. Ecological Applications 1993, 3, 294-306.

11. Garcia, D.; Quevedo, M.; Obeso, J.R.; Abajo, A. Fragmentation patterns and protection of montane forest in the Cantabrian range (NW Spain). Forest Ecology and Management 2005, 208, 29-43.

12. Wiens, J.A. Spatial scaling in ecology. Functional ecology 1989, 3, 385-397.

13. Tang, S.M.; Gustafson, E.J. Perception of scale in forest management planning: Challenges and implications. Landscape and urban planning 1997, 39, 1-9.

14. Mayer A.L.; Cameron, G.N. Consideration of grain and extent in landscape-scale studies of terrestrial vertebrate ecology. Landscape and Urban Planning 2003, 65, 201-217.

15. Wu, J. Effects of changing scale on landscape pattern analysis: scaling relations. Landscape Ecology 2004, 19, 125-138.

16. Buyantuyev, A.; Wu, J. Effects of thematic resolution on landscape pattern analysis. Landscape Ecology 2007, 22, 7-13.

17. García-Feced, C.; Saura, S.; Elena-Rosselló, R. Assessing the effect of scale on the ability of landscape structure metrics to discriminate landscape types in Mediterranean forest districts. Forest Systems 2010, 19, 129-140. 
18. Jazirehi, M.; Ebrahimi Restaghi, M. Silviculture in Zagros, University of Tehran Press: Tehran, Iran, 2003; (In Persian).

19. Wallach, A.; Inbar, M.; Lambert, R.; Cohen, S.; Shanas, U. Hand rearing Roe deer Capreolus capreolus: practice and research potential. International Zoo Yearbook 2007, 41, 183-193.

20 United States Geological Survey. Earth Resources Observation \& Science Center; USGS: Sioux Falls, USA, 2010; http, //earthexplorer.usgs.gov.

21. Tucker, C.J.; Grant, D.M.; Dykstra, J.D. NASA's global orthorectified Landsat data set. Photogrammetric Engineering and Remote Sensing 2004, 70, 313-322.

22. Chander, G.; Markham, B.L.; Helder, D.L. Summary of current radiometric calibration coefficients for Landsat MSS, TM, ETM ${ }^{+}$, and EO-1 ALI sensors. Remote Sensing of Environment 2009, 113, 893-903.

23. Huete, A.; Didan, K.; Miura, T.; Rodriguez, E.P.; Gao, X.; Ferreira, L.G. Overview of the radiometric and biophysical performance of the MODIS vegetation indices. Remote Sensing of Environment 2002, 83, 195-213.

24. Huete, A.; Liu, H. An error and sensitivity analysis of the atmospheric-and soil-correcting variants of the NDVI for the MODIS-EOS. Geoscience and Remote Sensing, IEEE Transactions 1994, 32, 897-905.

25. Rogan, J.; Franklin, J.; Roberts, D.A. A comparison of methods for monitoring multitemporal vegetation change using Thematic Mapper imagery. Remote Sensing of Environment 2002, 80, 143-156.

26. Zhao, G.; Maclean, A.L. A comparison of canonical discriminant analysis and principal component analysis for spectral transformation. Photogrammetric Engineering \& Remote Sensing 2000, 66, 841-847

27. Roberts, D.W.; Cooper, S.V. Concepts and techniques of vegetation mapping. In Land Classifications Based on Vegetation, Applications for Resource Management; USDA Forest Service General Technical Report: Ogden, USA, 1989; INT-257, pp. 90-96.

28. Bolstad, P.V.; Swank, W.; Vose, J. Predicting Southern Appalachian overstory vegetation with digital terrain data. Landscape Ecology 1998, 13, 271-283.

29. Farr, T.G.; Rosen, P.A.; Caro, E.; Crippen, R.; Duren, R.; Hensley, S.; Kobrick, M.; Paller, M.; Rodriguez, E.; Roth, L. The shuttle radar topography mission. Reviews of Geophysics 2007, 45, RG2004. Available online at http//dx.doi.org/10.1029/2005RG000183.

30. Breiman, L. Random Forests. Machine Learning 2001, 45, 5-32.

31. Lawrence, R. L.; Wood, S. D.; Sheley, R. L. Mapping invasive plants using hyperspectral imagery and Breiman Cutler classifications (RandomForest). Remote Sensing of Environment 2006, 100, 356-362.

32. Evans, J.; Cushman, S. A. Gradient modeling of conifer species using random forests. Landscape Ecology 2009, 24, 673-683.

33. Falkowski, M. J.; Evans, J. S.; Martinuzzi, S.; Gessler, P. E.; Hudak, A. T. Characterizing forest succession with LiDAR data: an evaluation for the Inland Northwest, USA. Remote Sensing of Environment 2009, 113, 946-956.

34. Falkowski, M. J.; Hudak, A. T.; Crookston, N. L.; Gessler, P. E.; Uebler, E. H.; Smith, A. Landscape-scale parameterization of a tree-level forest growth model: a k-nearest neighbor imputation approach incorporating LiDAR data. Canadian Journal of Forest Research 2010, 40, 184-199.

35. Falkowski, M. J; Manning, J. Parcel-based classification of agricultural crops via multi temporal Landsat imagery in support of habitat availability monitoring for western burrowing owls in the Imperial Valley agro-ecosystem. Canadian Journal of Remote Sensing 2011, 36, 750-762.

36. Earth Resource Data Analysis System (ERDAS). Erdas-Imagine v8.6 Tour Guide. ERDAS Inc.: Atlanta, Georgia, USA, 2010.

37. Environmental Systems Research Institute (ESRI). ArcMap version 9.3. ESRI Inc.: Redlands, California, USA, 2008.

38. Liaw, A.; Wiener, M. Classification and regression by Random-Forest. $R$ News 2002, 2, 18-22. 
39. R Development Core Team. R, A language and environment for statistical computing. $\mathrm{R}$ Foundation for Statistical Computing: Vienna, Austria, 2009. Available at the following web site http, //www.r-project.org.

40. McGarigal, K.; Cushman, S.A.; Neel, M.C.; Ene, E. FRAGSTATS, Spatial Pattern Analysis Program for Categorical Maps. Computer software program produced by the authors at the University of Massachusetts, Amherst, Massachusetts, USA, 2002. Available at the following web site http, //www.umass.edu/landeco/research/fragstats/fragstats.html.

41. Riitters, K.H.; O'neill, R.V.; Hunsaker, C.T.; Wickham, J.D.; Yankee, D.H.; Timmins, S.P.; Jones, K.B.; Jackson, B.L. A factor analysis of landscape pattern and structure metrics. Landscape Ecology 1995, 10, 23-39.

42. Tischendorf, L. Can landscape indices predict ecological processes consistently? Landscape Ecology 2001, 16, 235-254.

43. Osborne, J.W. Best practices in quantitative methods; Sage Publications Inc.: Thousand Oaks, California, USA, 2008.

44. Hurlbert, S.H. Pseudoreplication and the design of ecological field experiments. Ecological monographs 1984, 54,187-211.

45. Wilcoxon, F.; Katti, S.K.; Wilcox, R.A. Critical values and probability levels for the Wilcoxon rank sum test and the Wilcoxon signed rank test. Selected tables in mathematical statistics 1973, 1, 171-259.

46. Statistical Package for the Social Sciences (SPSS) Inc. SPSS Base 17.0 for Windows User's Guide, SPSS Inc.: Chicago, USA, 2008.

47. Kaiser, H.F. An index of factorial simplicity. Psychometrika 1974, 39, 31-36.

48. Krummel, J.R.; Gardner, R.H.; Sugihara, G.; O'neill, R.V.; Coleman, P.R. Landscape patterns in a disturbed environment. Oikos 1987, 48, 321-324.

49. Lam, N.S.N. Description and measurement of Landsat TM images using Fractals. Photogrammetric Engineering and Remote Sensing 1990, 56, 187-195.

50. Narumalani, S.; Mishra, D.R.; Rothwell, R.G. Change detection and landscape metrics for inferring anthropogenic processes in the greater EFMO area. Remote Sensing of Environment 2004, 91, 478-489.

51. Lambeck, R.J.; Hobbs, R.J. Landscape and regional planning for conservation: issues and practicalities. In Applying Landscape Ecology in Biological Conservation, Gutzwiller, K.J. Ed.; Springer-Verlag: New York, USA, 2002; pp. 360-380.

52. Ghazanfari, H.; Alizadeh, A.; Ataee, F. Preliminary evaluation of roe deer habitat in Bozin and Marakhil forests, Kermanshah province. Proceedings of the research achievements of the Department of Environment in the second national development plan, 1999, Tehran, Iran. (In Persian).

53. Walhström, L.K.; Kjellander, P. Ideal free distribution and natal dispersal in female roe deer. Oecologia 1995, 103, 302-308.

54. Tellería, J.L.; Virgós, E. Distribution of an increasing roe deer population in a fragmented Mediterranean landscape. Ecography 1997, 20, 247-252.

55. Wiens, J.A. Landscape ecology as a foundation for sustainable conservation. Landscape Ecology 2009, 24, 1053-1065.

56. Hewison, A.J.M.; Vincent, J.P.; Joachim, J.; Angibault, J.M.; Cargnelutti, B.; Cibien, C. The effects of woodland fragmentation and human activity on roe deer distribution in agricultural landscapes. Canadian journal of zoology 2001, 79, 679-689.

57. Jepsen, J.U.; Topping, C.J. Modelling roe deer (Capreolus capreolus) in a gradient of forest fragmentation: behavioural plasticity and choice of cover. Canadian journal of zoology, 2004, 82, 1528-1541.

58. Abbas, F.; Morellet, N.; Hewison, A.J.M.; Merlet, J.; Cargnelutti, B.; Lourtet, B.; Angibault, J.M.; Daufresne, T.; Aulagnier, S.; Verheyden, H. Landscape fragmentation generates spatial variation of diet composition and quality in a generalist herbivore. Oecologia 2011, 167, 401411. 
59. Serrano Ferron, E.; Verheyden, H.; Hummel, J.; Cargnelutti, B.; Lourtet, B.; Merlet, J.;

González-Candela, M.; Angibault, J.M.; Hewison, A.J.M.; Clauss, M. Digestive plasticity as a response to woodland fragmentation in roe deer. Ecological Research 2011, available online at: http://www.springerlink.com/content/y5m6602486417152/fulltext.html

60. Holland, J.D.; Bert, D.G.; Fahrig, L. Determining the spatial scale of species' response to habitat. BioScience 2004, 54, 227-233.

61. Saïd, S.; Gaillard, J.M.; Duncan, P.; Guillon, N.; Servanty, S.; Pellerin, M.; Lefeuvre, K.; Martin, C.; Laere, G. Ecological correlates of home range size in spring-summer for female roe deer (Capreolus capreolus) in a deciduous woodland. Journal of Zoology, 2005, 267, 301-308.

62. Ewers, R.M.; Rodrigues, A.S.L. Estimates of reserve effectiveness are confounded by leakage. Trends in Ecology and Evolution 2008, 23, 113-116.

63. Ferraro, P.J.; Hanauer, M.M.; Sims, K.R.E. Conditions associated with protected area success in conservation and poverty reduction. Proceedings of the National Academy of Sciences 2011, 108, 13913-13918.

(C) 2011 by the authors; licensee MDPI, Basel, Switzerland. This article is an open access article distributed under the terms and conditions of the Creative Commons Attribution license (http://creativecommons.org/licenses/by/3.0/). 